\title{
Angina pectoris-like pain provoked by intravenous adenosine in healthy volunteers
}

\author{
CHRISTER SYLVÉN， BJÖRN BEERMANN， BROR JONZON， RAGNAR BRANDT
}

\begin{abstract}
In a study to characterise the chest pain induced by adenosine this agent was given as a bolus into a peripheral vein to six healthy volunteers (five men) aged 30-44. On the first day the maximum tolerable dose was determined in each case. On the second day three doses of adenosine (one third, two thirds, and the full maximum tolerable dose) and three doses of saline were given single blind in randomised order. Thereafter aminophylline $5 \mathrm{mg} / \mathrm{kg}$ was given and the procedure repeated in a different randomised order. On the third day between two thirds and the full maximum tolerable dose was given followed by $10 \mathrm{mg}$ dipyridamole intravenously and a second injection of the same dose of adenosine. Heart rate and atrioventricular blocks were recorded by electrocardiography. One minute after each dose of adenosine the chest pain was scored.

The maximum tolerable dose of adenosine ranged from 10.6 to $37 \cdot 1 \mathrm{mg}$. All subjects experienced uneasy central chest pain provoking anxiety. The pain radiated to the shoulders, ulnar aspect of the arms, epigastric area, back, and into the throat. The pain began about 20 seconds after the injection and lasted 10-15 seconds. Increasing the dose of adenosine increased the intensity of the pain. Administration of aminophylline reduced the pain significantly. Second degree heart block was recorded in
\end{abstract}

Section of Cardiology, Department of Medicine, Karolinska Institute, Danderyd Hospital, Danderyd, Sweden

CHRISTER SYLVÉN, MD, PHD, associate professor

Section of Cardiology, Department of Medicine, Karolinska Institute, Huddinge Hospital, Huddinge

BJÖRN BEERMANN, MD, PHD, associate professor

Department of Pharmacology, Karolinska Institute, Stockholm BROR JONZON, MD, PHD, associate professor

Department of Clinical Physiology, Sabbatsberg Hospital, Stockholm RAGNAR BRANDT, MD, assistant professor

Correspondence to: Dr Christer Sylvén, Department of Medicine, Danderyd Hospital, S-182 88 Danderyd, Sweden. five of the six subjects during the time that the pain was experienced. After aminophylline no block was observed. Dipyridamole increased the intensity of pain. The duration of second degree heart block increased in four of the subjects, and in two of these third degree heart block occurred.

These findings suggest that adenosine released from the myocardium during ischaemia induces angina pectoris by stimulating theophylline sensitive receptors.

\section{Introduction}

Angina pectoris was first described by Heberden in $1772 .{ }^{1}$ Since then many attempts have been made to define its relation to ischaemia in the coronary vascular bed. The exact mechanism of angina pectoris in ischaemia, however, is unknown.

During ischaemia adenosine is formed from adenosine triphosphate and monophosphate within the ischaemic cell, from where it is released into the vascular bed. ${ }^{2}$ Within the bloodstream adenosine is cleared by vascular elements and has a half life of 10 seconds. ${ }^{3}$ Increased concentrations have been measured in blood from the coronary sinus during ischaemia..$^{45}$ Adenosine exhibits several cardioprotective effects during ischaemia mediated by cell surface receptors. ${ }^{6}$ Theophylline in therapeutic concentrations acts as an antagonist at some subtypes of adenosine receptors. ${ }^{78}$ Adenosine has vasodilatory properties within the coronary vascular bed $^{10}$ and inhibits platelet aggregation." In addition, adenosine inhibits calcium flow through the sarcolemma, ${ }^{12}$ so decreasing myocardial contractility and oxygen consumption. ${ }^{13}$ The nucleoside may also depress sinus node automaticity and atrioventricular conduction..$^{14} 15$

In addition to these protective effects against ischaemia, we report a study examining the hypothesis that adenosine causes angina pectoris as a further protection against myocardial ischaemia.

\section{Subjects and methods}

The study group comprised six healthy volunteers (five men) aged 30-44. None had a history of symptoms suggestive of heart disease.

On day 1 increasing doses of adenosine were injected rapidly into an 
antebrachial vein to find the maximum tolerable dose. Tolerability was judged from the subject's discomfort, as described below. A sterile solution of $5.3 \mathrm{mg}$ adenosine (Jansens Chemicals, Belgium) per ml saline was prepared by the hospital pharmacy. The initial dose was $2.65 \mathrm{mg}$ adenosine $(0.5 \mathrm{ml})$, increasing in steps of $0.5 \mathrm{ml}$. After each dose the vein was flushed with $5 \mathrm{ml}$ saline. The effects of adenosine disappeared within one minute and the subjects then rested for one to two minutes. Before being given the next dose they were asked whether any symptoms remained, and if not permission was obtained to continue with the experiment. If the subject did not wish to proceed further the last dose given was taken as the maximum tolerable.

For the experiments on day 2 the subjects abstained from xanthine containing food and drinks from $8 \mathrm{pm}$ the evening before. The subjects were given three doses of adenosine and three doses of placebo (saline) single blind and in randomised order. The doses were one third, two thirds, and the full maximum tolerable dose of adenosine. Aminophylline (Teofyllamin $23 \mathrm{mg} / \mathrm{ml}$, ACO, Sweden) $5 \mathrm{mg} / \mathrm{kg}$ was then given intravenously $(23 \mathrm{mg} /$ min). Five minutes after the injection venous blood was drawn for determination of the serum theophylline concentration. This was followed immediately by a new test with the three doses of adenosine and three doses of placebo given single blind and in randomised order.

On day 3 five of the subjects received an injection of between two thirds and the maximum tolerable dose of adenosine followed by $10 \mathrm{mg}$ dipyridamole (Persantin $5 \mathrm{mg} / \mathrm{ml}$, Boeringer Ingelheim, West Germany) intravenously over two to five minutes and then a further dose of adenosine.

One minute after each dose of adenosine or placebo central chest pain was quantified using the 0-9 point scale of Borg. ${ }^{16}$ The location and quality of the pain was documented on a whole body figure.

In all experiments a continuous electrocardiogram (Mingograf 61 ink jet recorder, Siemens Elema, Sweden) was recorded at $25 \mathrm{~mm} / \mathrm{s}$. The subjects were lying down during all experiments.

Analysis of electrocardiograms-Ten to 20 seconds after the injection of adenosine there was a slowing of the P-P wave interval. This was followed by a period of faster activity with maximal frequency of the interval 20-40 seconds after injection. The longest and shortest P-P wave intervals were identified and recorded. The longest P-P interval was defined as the point of maximal adenosine effect with respect to chest pain and atrioventricular block.

Statistics-Data are expressed as means and standard deviation (SD). Paired Student's $t$ test was used to test the rejection of the null hypothesis between different measurements.

Ethics-The study was approved by the local ethical committee. All experiments were performed in a fully equipped coronary care unit. The volunteers were all doctors of internal medicine, and the background and procedure of the study were thoroughly explained beforehand. All the volunteers tested completed the protocol.

\section{Results}

Table I gives the clinical characteristics of the volunteers, the maximum tolerable doses of adenosine, and the serum theophylline concentrations recorded. All subjects experienced deep central chest pain with increasing

TABLE 1-Characteristics of volunteers, maximum tolerable doses of adenosine, and concentrations of theophylline in serum

\begin{tabular}{cccccc}
\hline $\begin{array}{c}\text { Subject } \\
\text { No }\end{array}$ & $\begin{array}{c}\text { Age } \\
\text { (years) }\end{array}$ & Sex & $\begin{array}{c}\text { Weight } \\
(\mathbf{k g})\end{array}$ & $\begin{array}{c}\text { Maximum } \\
\text { tolerable } \\
\text { dose of adenosine } \\
(\mathbf{m g})\end{array}$ & $\begin{array}{c}\text { Serum } \\
\text { theophylline } \\
\text { concentration } \\
(\mu \mathrm{mol} / \mathrm{l})\end{array}$ \\
\hline 1 & 44 & $\mathbf{M}$ & 73 & $15 \cdot 9$ & 63 \\
2 & 40 & $\mathbf{M}$ & 75 & $15 \cdot 9$ & 44 \\
3 & 30 & $\mathbf{M}$ & 75 & $13 \cdot 3$ & 62 \\
4 & 41 & $\mathbf{M}$ & 65 & $37 \cdot 1$ & 58 \\
5 & 35 & $\mathbf{M}$ & 75 & $10 \cdot 6$ & 40 \\
6 & 35 & F & 50 & $13 \cdot 3$ & 32 \\
\hline
\end{tabular}

Conversion: SI to traditional units—Theophylline: $1 \mu \mathrm{mol} / \mathrm{l} \approx 0 \cdot 17 \mu \mathrm{g} / \mathrm{ml}$.

doses of adenosine. The pain began about 20 seconds after the injection and lasted 10-15 seconds. Table II shows the quality and location of the pain. None of the subjects had had a similar pain before. It was associated with feelings of anxiety and unease and was located deep in the centre of the chest, radiating in different directions-up into the throat, to the shoulders, and along the ulnar aspect of the upper and lower arms. The maximum tolerable doses varied widely among the subjects (table I). Figure 1 shows the relation between dose and the severity of the chest pain rated using the Borg scale in the six subjects receiving increasing doses of adenosine single blind. Befored administration of aminophylline a positive linear relation was observed in four subjects. For the whole group the score was significantly higher $(p<0.05)$ after the maximum dose of adenosine as compared with the lowes? dose. After aminophylline a positive linear dose response relation was found $\bar{P}$ in all subjects $(p<0.01)$. Administration of aminophylline resulted

TABLE II-Quality and location of chest pain in volunteers

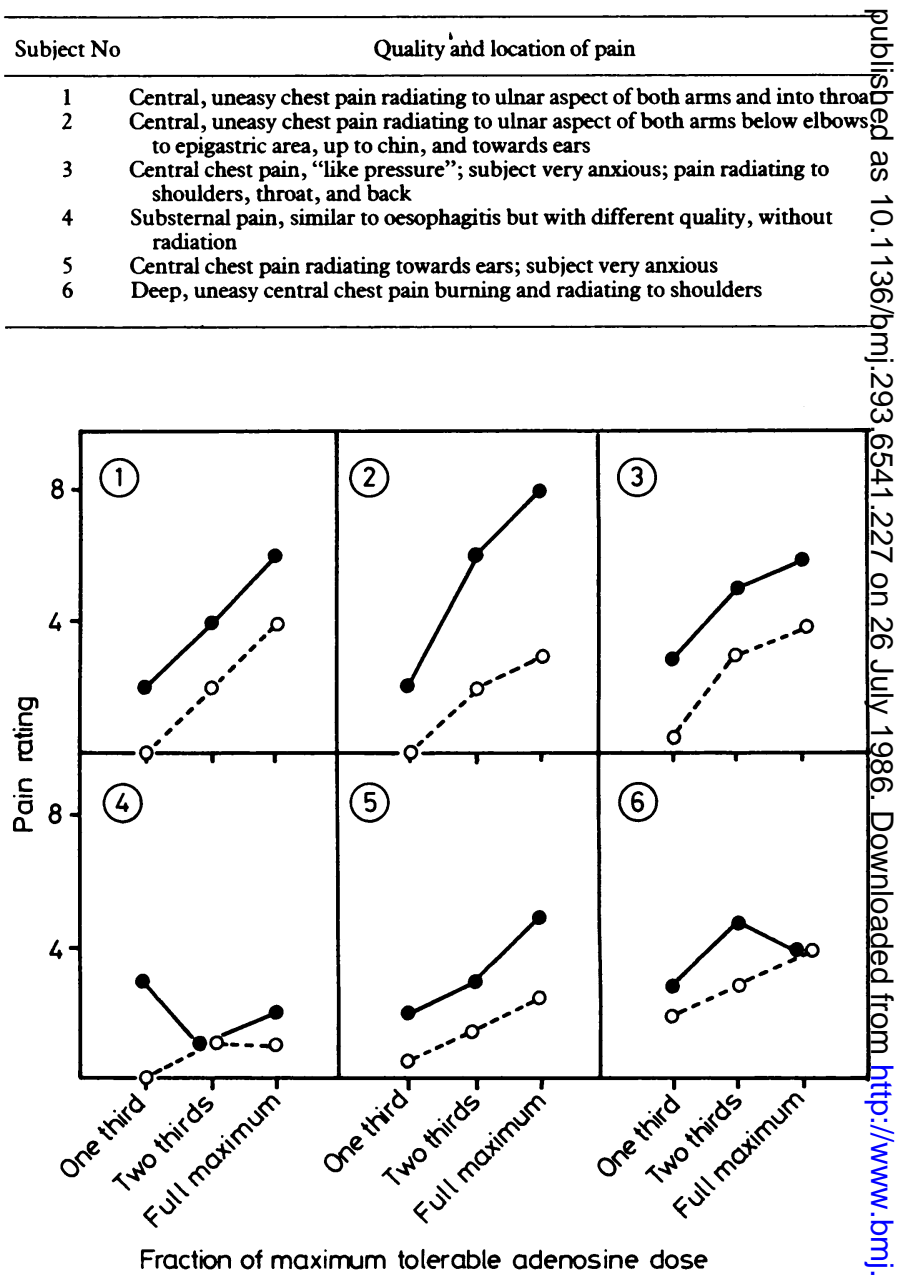

FIG 1-Rating of central chest pain according to Borg scale (0-9) after thrę intravenous doses of adenosine in subjects 1 to 6 before (-) and after (O - . - ) aminophylline. Adenosine given as rapid bolus injection of one thirde two thirds, and full maximum tolerable dose.

TABLE III-P-P Wave intervals $(s)$ after increasing doses of adenosine before and aftes aminophylline administration at start of adenosine injection and at maximal adenosintu effects. Figures are means (SD)

\begin{tabular}{|c|c|c|c|}
\hline \multirow{2}{*}{$\begin{array}{l}\text { Fraction of maximum } \\
\text { tolerated adenosine } \\
\text { dose }\end{array}$} & \multirow[b]{2}{*}{ Start of injection } & \multicolumn{2}{|c|}{ Maximal adenosine effect } \\
\hline & & Long P-P interval & Short P-P interval \\
\hline \multicolumn{4}{|c|}{ Before aminophylline } \\
\hline $\begin{array}{l}\text { One third } \\
\text { Two thirds } \\
\text { Full maximum }\end{array}$ & $\begin{array}{l}0.86(0.17)^{\star}+H \\
0.89(0.12)+H+ \\
0.86(0.10)+H\end{array}$ & $\begin{array}{l}1.04(0.22)^{\star \star} \\
1.00(0.26)^{\star \star} \\
0.98(0.23)^{\star \star}\end{array}$ & $\begin{array}{l}0.66(0.11) \\
0.66(0.13) \\
0.56(0.08)\end{array}$ \\
\hline \multicolumn{4}{|c|}{ After aminophylline } \\
\hline $\begin{array}{l}\text { One third } \\
\text { Two thirds } \\
\text { Full maximum }\end{array}$ & $\begin{array}{l}0.87(0.15)^{\star}+t \\
0.86(0.14)^{\star}+t \\
0.88(0.16)^{\star \star}+H\end{array}$ & $\begin{array}{l}1.03(0.12)^{\star \star} \\
1.01(0.07)^{\star \star \star} \\
1.01(0.14)^{\star \star \star}\end{array}$ & $\begin{array}{l}0.72(0.15) \\
0.64(0.13) \\
0.66(0.09)\end{array}$ \\
\hline
\end{tabular}

Difference between successive measurements: ${ }^{\star} p<0.05 ;{ }^{\star \star} p<0.01 ;{ }^{\star \star \star} p<0.001$ Difference between start of injection and shortest P-P interval: $t \mathrm{p}<0.05 ; \mathrm{Hp}<0.01$; $+t p<0.001$ 


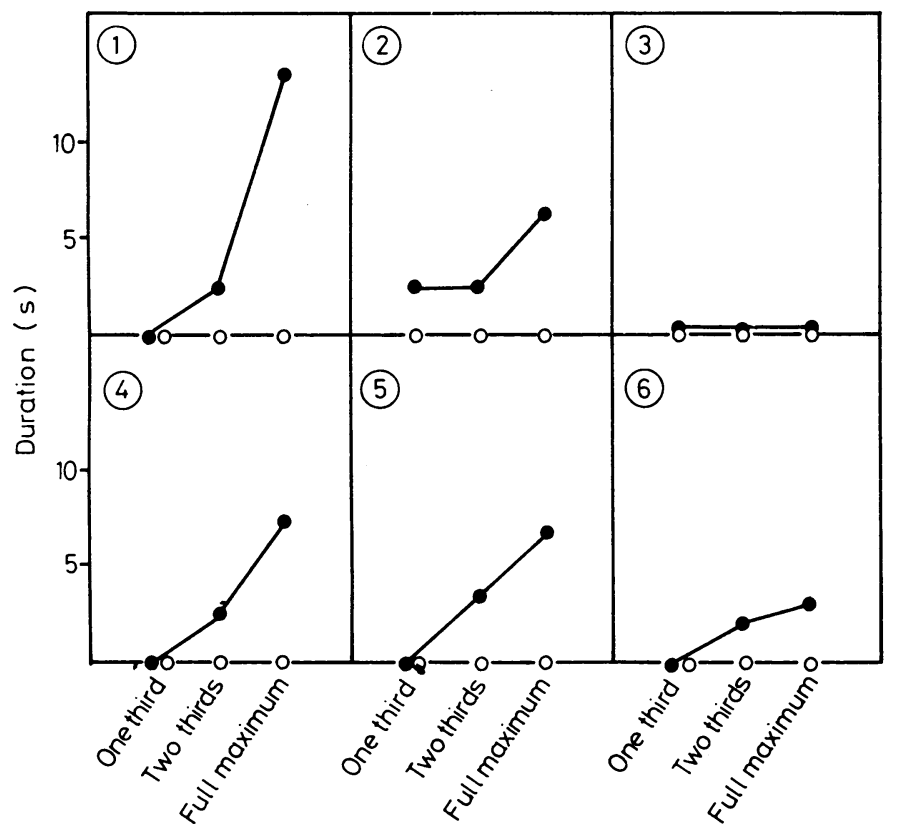

Fraction of maximum tolerable adenosine dose

FIG 2-Duration of second degree heart block or sinus arrest in subjects 1 to 6 before ( ) and after $\left(\mathrm{O}-\mathrm{O}^{-}\right)$aminophylline.
Had the subjects not known how quickly the discomfort would pass they would have refused further injections of adenosine. The pain provoked by an intravenous injection of adenosine had all the characteristics of angina pectoris. All but one of the subjects showed a dose response relation. The exception tolerated more than twice the dose of adenosine compared with the other subjects, suggesting differences in sensitivity to adenosine. The angina pectoris-like pain lasted 10-15 seconds, during which adenosine also provoked second degree atrioventricular block. ${ }^{14}$

In a few subjects blood pressure was measured by cuff. No change was observed during the period of maximal pain. Owing to the short duration of the adenosine effect, however, more reliable blood pressure measurements may require intra-arterial recording. This was not considered necessary in our study.

The discomfort and pain reported here were provoked by bolus doses of adenosine. The dose range has been used by others in studies of the atrioventricular blocking effect of adenosine $\mathrm{e}^{14}$ and of its stimulatory action on respiration. ${ }^{17}$ In the latter investigation, however, Watt and Routledge reported a feeling of suffocation or of chest, abdominal, or neck discomfort as a side effect of adenosine. This unpleasant feeling in the chest or in the vicinity of the chest with elements of anxiety were similar to the findings in our subjects. Watt and Routledge, however, did not regard the finding as having any pathophysiological importance.

Theophylline blocks adenosine receptors. ${ }^{6}$ After administration of aminophylline resulting in therapeutic theophylline serum concentrations all subjects experienced less severe angina pectoris-

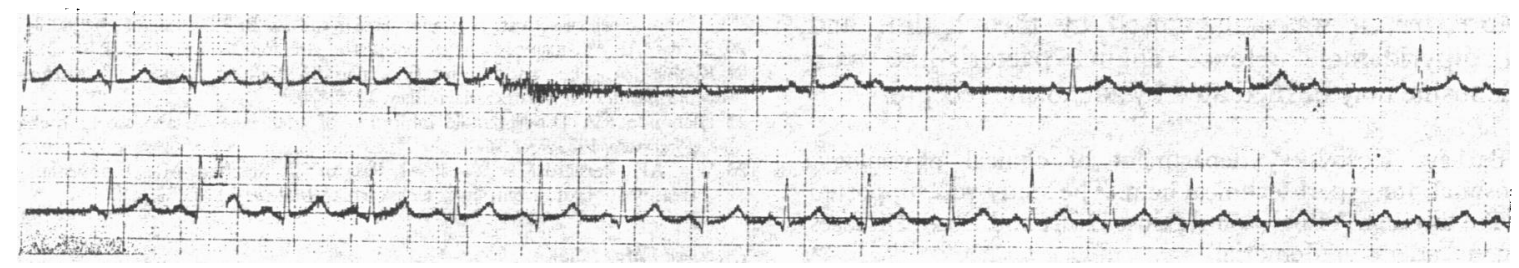

FIG 3-Tracing of second degree atrioventricular block after intravenous bolus injection of adenosine.

in therapeutic serum concentrations of theophylline (mean (SD) 50 (13) $\mu \mathrm{mol} / 1 ; 8.3(2 \cdot 2) \mu \mathrm{g} / \mathrm{ml})$ and caused a decreased response to the three doses of adenosine-at the lowest dose $35(24) \%(p<0.05)$; at the medium dose $41(22) \%(p<0.01)$; at the highest dose $82(26) \%(p<0.01)$.

Table III shows the variations in P-P wave intervals. A slight prolongation (10-20\%) of the P-P interval occurred 10-20 seconds after the injection of adenosine. This was followed by a shortening of the P-P interval (30-40\%) with maximal effect $20-40$ seconds after injection. Variations in the P-P interval were unchanged after aminophylline. Adenosine induced second degree atrioventricular heart block in all except subject 3 (figs 2, 3). In addition, subject 2 developed sinus arrest. After aminophylline no conduction disturbances were observed.

Dipyridamole increased the chest pain in all five subjects tested (fig 4) and enhanced the effect of adenosine on atrioventricular conduction. Third degree heart block was observed for 4.3 and 6.0 seconds respectively in subjects 2 and 4 . In addition, these two subjects had second degree block for $9 \cdot 3$ and $9 \cdot 8$ seconds. Subject 3 did not develop heart block. The remaining two subjects had second degree heart block lasting about three times longer than before dipyridamole (10.4 and 15.7 seconds). Variations in P-P interval did not differ before and after dipyridamole.

No changes in the ST-T segment of the electrocardiogram were observed in any instance.

\section{Discussion}

All subjects tested experienced deep central chest pain radiating in different directions-towards the ears, shoulders, ulnar aspect of the upper and lower arms, back, and upper abdomen. The character of the pain was similar to that of other types of pain-for example, of oesophagitis-but there were also elements of pressure, unease, and anxiety not previously experienced by any of the subjects tested.
FIG 4-Rating of central chest pain according to Borg scale (0-9) after single intravenous dose of adenosine before and after $10 \mathrm{mg}$ dipyridamole given intravenously. Adenosine given as two thirds to full maximum tolerable dose. 
like pain, suggesting that the pain induced by adenosine is at least to some degree dependent on activation of theophylline sensitive receptors. The effect of adenosine on atrioventricular nodal conduction, however, was completely antagonised by theophylline. Thus the angina pectoris-like effect of adenosine is less sensitive to theophylline than the effect of adenosine on atrioventricular conduction. This observation might well be explained by pharmacokinetic differences, but differences at the receptor level are also possible. Generally adenosine receptors exert depressant effects on different physiological functions. McQueen and Ribeiro, however, reported finding theophylline resistant chemoreceptors within the carotid sinus, where adenosine acts as a stimulator. ${ }^{18} 19$ Hypothetically the induction of angina pectoris-like pain by adenosine may partly be mediated by similar receptors. In this context we note that adenosine has an established role as a neuromodulator. ${ }^{20}$

In view of these findings the role of theophylline derivates in the treatment of coronary insufficiency must be questioned. ${ }^{21}$ Theophylline most probably counteracts different cardioprotective effects of adenosine such as coronary vasodilatation. Moreover, if adenosine induces angina pectoris this warning signal probably appears only at more severe degrees of ischaemia if the adenosine receptors are blocked by theophylline.

Dipyridamole inhibits the cellular uptake of adenosine. ${ }^{22}$ After receiving dipyridamole all subjects experienced increased angina pectoris-like pain and showed increased duration and degree of heart block. ${ }^{23}$ This finding further supports the hypothesis that the observed effects of adenosine are mediated by adenosine receptors and not by intracellular effects of adenosine.

In this study angina pectoris-like pain provoked by intravenous adenosine was shown to be dependent on the concentration of adenosine. Moreover, it was antagonised by theophylline and enhanced by dipyridamole. Hence angina pectoris-like pain induced by adenosine may be mediated by adenosine receptors.

We thank Barbara Kosovsky, department of clinical physiology, Sabbatsberg Hospital, for expert technical help. The study was supported by grants from the Swedish Association Against Heart and Lung Diseases and from the Egon Andersson Memorial.

\section{References}

Heberden W. Some account of a disorder of the breast. Medical Transactions 1772;2:59-67.

2 Arch JRS, Newsholme EA. The control of the metabolism and hormonal role of adenosine. In: Campbell PN, Aldridge WN, eds. Essays in biochemistry. Vol 14. New York: Academic Press, $\subset$ 1978:82-123.

3 Fredholm BB, Sollevi A. The release of adenosine and inosine from canine subcutaneous adipose tissue by nerve stimulation and noradrenaline. $\mathcal{F}$ Physiol (Lond) 1981;313:351-67. 4 Kuz'min AI, Saprygina TV, Vakhliaev VD, Kukes VG, Syrkin AL. Effect of myocardial ischemia गु

5 Edlund A, Berglund B, van Dorne D, et al. Coronary flow regulation in patients with ischemic $\$$ heart disease: release of purines and prostacyclin and the effect of inhibitors of prostaglandin formation. Circulation 1985;71:1113-20.

6 Burnstock G, ed. Receptors and recognition. In: Purinergic receptors. Ser B. London: Chapman and Hall, 1981:12.

7 Fredholm BB. Are methylxanthine effects due to antagonism of endogenous adenosine? Trends in $\stackrel{\oplus}{+}$ Pharmacological Sciences 1980;1:129-32.

8 Rall TW. Central nervous stimulants. In: Goodman AG, Gilman LS, Goodman A, eds. The pharmacological basis of therapeutics. New York: Macmillan, 1980:592-607.

9 Drury AN, Szent-Györgyi A. The physiological activity of adenine compounds with special $\frac{\bar{S}}{D}$ reference to their action upon the mammalian heart. $\mathcal{P}$ Physiol 1929;68:213-37.

10 Schrader J, Thompson CI, Hiendelmayer G, Gerlach E. Role of purines in acetylcholine induced coronary vasodilatation. $\mathcal{I}$ Mol Cell Cardiol 1982;14:427-30.

11 Mills DCB, MacFarlane DE, Lemmex BWG, Haslam RJ. Receptors for neucleosides and nucleotides on blood platelets. In: Berne RM, Rall TW, Rubio R, eds. Developments in $\vec{O}$ pharmacology. Vol 2. The Hague: Martinus Nijhoff, 1983:277-89.

12 Fenton RA, Bruttig SP, Rubio R, Berne RM. Effect of adenosine on calcium uptake by intact and $\overrightarrow{\vec{\omega}}$ cultured vascular smooth muscle. Am f Physiol 1982;242:1797-1804.

13 Sylvén JC, Armour JA, Klassen GA. Flow and pressure responses of coronary arteries and veins to vasodilating agents. Can f Physiol Pharmacol 1984;62:1365-73.

14 Di Marco JP, Sellers T, Berne RM, West GA, Belardinelli L. Adenosine: electrophysiological effects and therapeutic use for terminating paroxysmal supraventricular tachycardia. IN Circulation 1983;68:1254-63.

15 Berne RM, Di Marco JP, Belardinelli L. Dromotropic ffects of adenosine and adenosine $\omega$ antagonists in the treatment of cardiac arrhythmias involving the atrioventricular node. Of Circulation 1984;69:1195-7.

16 Borg G. The determination of subjective intensities in verbal description of symptoms. Reports from the Institute of Applied Psychology, the University of Stockholm 1976;75:1-22.

1 Watt AH, Routledge PA. Adenosine stimulates respiration in man. Br $f$ Clin Pharmacol 1985;20:503-6.

$18 \mathrm{McQueen}$ DS, Ribeiro JA. Effect of adenosine on carotid chemoreceptor activity in the cat. $\mathrm{Br} \mathcal{Y}$ 윽 Pharmacol 1981;74:129-36.

19 McQueen DS, Ribeiro JA. On the specificity and type of receptor involved in carotid body $\widetilde{\sigma}$ chemoreceptor activation by adenosine in the cat. $\mathrm{Br} \mathcal{X}$ Pharmacol 1983;80:347-54.

20 Snyder SH. Adenosine as a neuromodulator. Ann Rev Neurosci 1985;8:103-24.

21 Ritchie JM. The xantines. In: Goodman LS, Gilman A, eds. The pharmacological basis of therapeutics. New York: Macmillan, 1975:370.

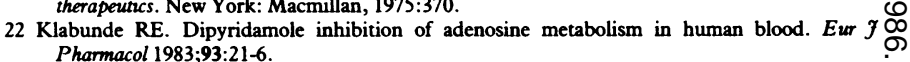

23 Watt AH, Bernard MS, Webster J, Passani SL, Stephens MR. Intravenous adenosine in the $\square$ treatment of supraventricular tachycardia. Br Hearn $\mathcal{F}$ 1985;53:678.

(Accepted 7 May 1986)

\section{YEARS AGO}

As civilisation advances, and as intellectual requirements increase, the share of suffering which falls to the lot of individuals seems to be doomed to augmentation. The psalmist tells us that "in much wisdom is much grief, and he that increaseth knowledge increaseth sorrow," and this is true in more ways than one. Apart from the number, each year more formidable, of those whose nervous organisation succumbs to the extra demands of an exacting age, it would appear that the pains of child-birth are directly in proportion to the cerebral development of the foetus. Such, at least, is the ingenious theory advanced by a modern writer on obstetrics, in America, who explains thus the comparative immunity from pain of the females of savage races. It is difficult to know, for certain, how far this alleged immunity from pain on the part of savage females may be regarded as proved; but the suggestion is rather enticing at first sight. Not, indeed, that the amount of pain during a given labour could ever be accepted as a criterion of the cerebral development of the forthcoming infant; for the estimation of pain is difficult, as matters stand at present, and would become infinitely more so if the idea obtained general acceptation that the intelligence of the child could be guaged, to some extent, by the evidence of pain afforded by the mother. This increase of grief was, probably, not that foretold in the above quotation, but it may possibly, in reality, constitute the female share of the malediction. On this hypothesis, one shudders to think of the throes that must have accompanied the birth of a Milton or a Shakespeare, and mothers have every reason to be thankful that geniuses of their calibre are rare indeed. The statistics, necessary to prove or disprove this theory, would unfortunately be exceedingly difficult to obtain, particularly if the object of the inquiries became known to the mothers. Women are not, as a rule, prone to underrate the sufferings through which they have gone, nor would they be likely to do so if they thought any importance were to be attached to their amount. Those women whose abnegation does not extend to an increase of pain, in view of a child possessing more than ordinary intellectualo endowments, will probably seek to avoid such "unearned increment," by marriage with men more remarkable for their physical vigour, than for their 0 mental acumen, and whose heads, accordingly, had never inflicted un-음 necessary pain on a suffering mother. Such a policy, however, is, from a N physiological point of view, simply suicidal; it would be far preferable to $D$ marry a poet, whose son has so many chances of being an idiot, according to음 popular belief. (British Medical fournal 1886;i:837.)

We have often expressed the opinion that underfeeding rather than overpressure lay at the root of those symptoms experienced by some of the children of our Board Schools, which have been so readily ascribed to this latter cause. It is, therefore, with great satisfaction that we see that as movement for providing free dinners is again about to be taken up in Southwark to meet the exigencies of the coming winter. The recipients of this benevolence included not only the poor children attending the Board $\frac{\mathbb{D}}{\mathbb{D}}$ Schools, but other children of the neighbourhood who required sustenance, $\stackrel{?}{\square}$ and who were unable to pay any sum, however small, for even the common necessaries of life. As a preliminary step in the efforts towards meeting the anticipated distress, the Secretary of the Farm House Committee (Mr. Thomas Hunter) had paid visits throughout the locality, and has, in severalo instances, received reports of a most distressing character. It is intended to inaugurate the "free dinner" season early in the first week of November, the Committee (who have made no public appeal for aid) being desirous to? render timely succour to the poverty-stricken children before the cold winter overtakes them. (British Medical fournal 1886;ii:831.) 